\title{
VIDEO-LECCIONES Y EVALUACIÓN FORMATIVA: UNA PRÁCTICA EN EDUCACIÓN FÍSICA
}

Video-lessons and formative assessment: a practice in physical education

Video-aulas e avaliação formativa: uma prática em educação física

\section{David Recio Rodríguez}

IESO Pinares de Pedrajas (Pedrajas de San Esteban, Valladolid), +34 690181432 y davidrecio24@hotmail.com

\begin{abstract}
Resumen
La presente comunicación muestra una forma de trabajar en las clases de Educación Física, en la que se conjugan la evaluación formativa y una metodología en auge que parte de las premisas de las aulas invertidas a la par que se le otorga una serie de matices diferentes. Para ello, la comunicación parte del trabajo realizado en una unidad didáctica (UD) sobre frisbee ultimate, donde a los alumnos se les pide que realicen una video-lección en grupos, que al mismo tiempo se ve inmersa en un proceso de evaluación formativa con tres niveles de actuación. Estos procesos permiten al alumno mejorar su trabajo inicial al ir recibiendo información de un instrumento de evaluación objetivo manejado en un primer momento por el propio grupo, a continuación por otro grupo y finalmente por el docente.

Palabras clave: Evaluación formativa; video-lección; aulas invertidas
\end{abstract}

\begin{abstract}
This communication tries to show a different way of working in Physical Education classes, where formative evaluation is combined with a booming methodology that starts from the premises of the flipped classrooms. But this methodology is used with some different nuances. To do this, the communication starts from the work done in a didactic unit (UD) about ultimate frisbee, where the students are requested to make a video-lesson in groups. At the same time, the students are immersed in a process of formative evaluation with three levels of actions. These processes allow students to improve their initial work because they receive information from an objective
\end{abstract}


evaluation tool. This tool is initially handled by the group itself, then by another group and finally by the teacher.

Keywords: Formative assessment; video-lesson; flipped classrooms

\section{Resumo}

Este artigo descreve uma forma de trabalharem aulas de educação física, em que a avaliação formativa e metodologia crescendo combinar que parte das instalações da sala de aula invertida, ao mesmo tempo é dado um número de diferentes tons. Para este fim, a comunicação do trabalho realizado em uma unidade didática de (UD) sobre Ultimate Frisbee, onde os alunos são convidados a fazer um vídeo-aula em grupos, ao mesmo tempo, está imerso em um processo de avaliação formativa com três níveis de ação. Estes processos permitem que os alunos a melhorar seu relatório inicial para ser receber informações de um instrumento de avaliação objetiva inicialmente tratado pelo próprio grupo, em seguida, por outro grupo e, finalmente, o ensino.

Palavras-chave: Avaliação formativa; vídeo-aula; salas de aula invertida

\section{Introducción}

La legislación educativa actual (LOMCE, 2013, RD 1105/2014) requiere que la evaluación en la ESO sea entre otros aspectos formativa, con el fin de mejorar los procesos de enseñanza-aprendizaje que tienen lugar. Según López-Pastor (2006), la evaluación formativa es todo proceso que permite al profesor obtener información de los proceso de aprendizaje de sus alumnos ${ }^{1}$ para ayudarles a aprender más y/o corregir sus errores, proporcionándoles feedback y al mismo tiempo mejorar la propia práctica docente.

En esta ocasión, para poder llevar a cabo un proceso de evaluación formativa, se les solicita a los alumnos la realización de una video-lección sobre un aspecto concreto de un deporte, siendo ésta vez el frisbee ultimate el elegido. Se escoge este deporte porque en el centro donde se realiza la experiencia los alumnos no han tenido un gran contacto con él, lo que facilita que todos partan de un nivel homogéneo, aunque realmente se podría plantear con cualquier otro.

\footnotetext{
${ }^{1}$ La utilización del género masculino a lo largo del presente documento se realiza exclusivamente por una cuestión de fluidez. 
En lo referente a las video-lecciones, existen múltiples plataformas que abogan por su uso, (YouTube Edu, Mitx, Uncollege de Stanford, Khan Academy, etc.), y autores que utilizan este tipo de herramientas, asociadas generalmente a las denominadas flipped classroom o aulas invertidas (Bergmann \& Sams, 2011, 2012; Fornons \& Palau, 2016; Jamaludin \& Osman, 2014; Prieto, 2016). Según Viñas (2011), Khanpropone que sea el profesor quien establezca qué videos tienen que ver los estudiantes en su casa, favoreciendo que puedan llevar su propio ritmo de trabajo. De esta forma, en clase, se hacen los deberes y el profesor y los otros compañeros ayudan a quién más lo necesita. Sobre estas mismas premisas, también se asientan las aulas invertidas, aunque no solamente a través de videos sino además con podcasts y documentos electrónicos (Prieto, 2016).

Por lo tanto, de la unión de estos tres elementos (video-lecciones, evaluación formativa y frisbee-ultimate), se busca generar una experiencia que favorezca la autonomía de los alumnos, implicándoles en su propio proceso de aprendizaje.

\section{Contextualización}

La propuesta que se presenta parte del trabajo realizado en una UD sobre frisbee ultimate para $2^{\circ}$ de ESO en el IESO Pinares de Pedrajas (Pedrajas de San Esteban, Valladolid).

\section{Diseño y desarrollo}

El trabajo que se les solicita es la elaboración de una video-lección acompañada de un guion de lo que se va a exponer y que tienen que preparar en grupos, donde tienen que explicar un aspecto concreto sobre el frisbee ultimate (por ejemplo, un tipo de lanzamiento, orígenes, etc.). Cada miembro del grupo deberá probar, al menos una vez, a ser “el profesor del video”. No obstante, para preparar esa información, el profesor les otorga documentos con los que poder trabajar. Una vez que todos lo han practicado, será el propio grupo quien escoja a su representante final. Entonces se lleva a cabo el primer proceso de evaluación formativa mediante una coevaluación intragrupal. Después, cada grupo se une a otro y se lleva a cabo una coevaluación intergrupal; y, por último, el profesor realiza una heteroevaluación antes de la calificación final. Para llevar a cabo estos procesos de evaluación el profesor les entrega una escala de valoración (tabla 1, modificada de Pérez-Pueyo \& Casado, 2015) donde se recogen una serie de aspectos e indicadores de logro. 
Tabla 1.

Escala de valoración de la video-lección (modificada de Pérez-Pueyo \& Casado, 2015)

\begin{tabular}{|c|c|}
\hline \multicolumn{2}{|l|}{ Aspectos a evaluar } \\
\hline \multicolumn{2}{|l|}{ PRESENTACIÓN (30 puntos) } \\
\hline Presentan el contenido solicitado (por ejemplo, se tratan todos los apartados de un tema). & 30 \\
\hline $\begin{array}{l}\text { Presentan el contenido solicitado de manera casi completa (por ejemplo, se tratan todos los } \\
\text { apartados de un tema aunque en algunos casos de manera superficial). }\end{array}$ & 25 \\
\hline $\begin{array}{l}\text { Presentan el contenido de manera incompleta (Por ejemplo, algunos apartados del tema no se } \\
\text { tratan). }\end{array}$ & 15 \\
\hline $\begin{array}{l}\text { No se presentan el contenido mínimo o la información básica. Independientemente de los } \\
\text { miembros que participen. No hay coherencia. }\end{array}$ & 5 \\
\hline \multicolumn{2}{|l|}{ DURACIÓN (15 puntos) } \\
\hline La explicación no excede los 3 minutos. & 15 \\
\hline La explicación no excede los 3 min. pero hay partes que sobran. & 12 \\
\hline La explicación excede los 3 min, pero nunca de 4 y hay cosas que sobran. & 7,5 \\
\hline $\begin{array}{l}\text { La explicación excede los } 3 \text { minutos, hay muchos elementos de relleno que no aportan nada } \\
\text { útil al tema. }\end{array}$ & 0 \\
\hline \multicolumn{2}{|l|}{ CONTENIDO (30 puntos) } \\
\hline $\begin{array}{l}\text { Hay lógica en el contado y se destacan los aspectos importantes a tener en cuenta. Hay } \\
\text { coherencia entre lo que se expone y el guion presentado. }\end{array}$ & 30 \\
\hline $\begin{array}{l}\text { En algunos momentos se pierde la lógica en el contado y no se destacan/resaltan aspectos } \\
\text { importantes a tener en cuenta. Se presentó guion pero no se cuadra exactamente con lo que } \\
\text { exponen. }\end{array}$ & 25 \\
\hline $\begin{array}{l}\text { No se observa una lógica del contado ni se destacan la mayoría de aspectos importantes a } \\
\text { tener en cuenta. No se presentó el guion. }\end{array}$ & 15 \\
\hline No hay explicaciones ni/o comentarios explicativos. & 0 \\
\hline \multicolumn{2}{|l|}{ GUION (15 puntos) } \\
\hline $\begin{array}{l}\text { Se presenta un guion que resume los puntos y la información que se va a tratar y éste es } \\
\text { seguido en el video. En este guion además se refleja los participantes del grupo, el centro, la } \\
\text { asignatura y el curso. }\end{array}$ & 15 \\
\hline Se presenta un guion pero no se ve reflejado en el video. & 7,5 \\
\hline No se presenta un guion. & 0 \\
\hline \multicolumn{2}{|l|}{ GRABACIÓN (10 puntos) } \\
\hline La calidad de la grabación y el cuidado del vídeo son destacables. & 10 \\
\hline La calidad de la grabación y el cuidado del vídeo son mejorables pero suficientes. & 5 \\
\hline La grabación y el cuidado del vídeo se deben trabajar mucho más. & 0 \\
\hline
\end{tabular}

Por lo tanto, la idea propuesta para trabajar se fundamenta en gran parte en las metodologías descritas en la Khan Academy y las clases invertidas, pero con dos diferencias. La primera es que una vez estén todos los vídeos que han sido elaborados durante las clases por los alumnos, el profesor empezará a trabajar los contenidos del frisbee ultimate, y cada día pondrá al principio de la clase uno de ellos. A continuación, 
complementará la información que considere necesaria y llevará a cabo las actividades planificadas.

La segunda diferencia es que en vez de ser usado para preparar los deberes, esos vídeos serán de donde los alumnos saquen las preguntas para el examen. Pero de una forma particular, y basado en la propuesta de Pérez-Pueyo et al. (2013)². Cuando el profesor ya haya trabajado todos elementos previstos, pondrá de nuevo todos los vídeos en clase. Ahora siguiendo la idea de Pérez-Pueyo et al. (2013) en los mismos grupos de trabajo, cada grupo deberá sacar al menos cinco preguntas con sus respectivas respuestas, de las cuales dos deben ser de calidad ${ }^{3}$, y con todas esas preguntas se forma un documento que será el que tendrán que estudiar para el examen.

\section{Evaluación y conclusiones}

El video que se les solicita no debe exceder de los tres minutos, por lo que la información con la que tienen que trabajar no es elevada, se busca una explicación breve y clara.

En un primer momento se genera una disonancia al alumno al verse sorprendido por el hecho de “cómo es que el profesor no explica nada”. En realidad, lo que se busca es favorecer que se impliquen en sus propios procesos de aprendizaje, que empiecen a trabajar un contenido concreto, que ellos mismos le van a ir dando forma y entre ellos se van a ir mejorando, siempre supervisados por el profesor y teniendo como guía el instrumento proporcionado.

Cuando el profesor se pone a explicar la UD (una vez terminado los videos), los alumnos ya conocen qué se va a trabajar y entienden mejor el porqué de las cosas. Por lo tanto, la experiencia se puede considerar fácil de llevar a cabo, efectiva y en gran parte innovadora.

\section{Referencias}

Bergmann, J., \& Sams, A. (2011). How the flipped classroom is radically transforming learning. The Daily Riff. Recuperado de http://www.thedailyriff.com/articles/howthe-flipped-classroom-is-radically-transforming-learning-536.php

\footnotetext{
${ }^{2}$ Se recomienda leer Pérez-Pueyo et al. (2013) para profundizar sobre la propuesta citada.

${ }^{3}$ Se entiende por pregunta de calidad siguiendo a Pérez et al. (2013), aquellas que relacionan conceptos y que no encontramos literalmente en un texto. 
Bergmann, J., \& Sams, A. (2012). Flip your classroom: Reach every student in every class every day. United States of America: International Society for Technology in Education.

Fornons, V. \& Palau, R. F. (2016). Flipped classroom en la asignatura de matemáticas de $3^{\circ}$ de educación secundaria obligatoria. EDUTEC, Revista Electrónica de Tecnología Educativa, $55 . \quad$ Recuperado de http://www.edutec.es/revista/index.php/edutece/article/view/284/Edutec_n55_Fornons_Palau

Jamaludin, R., \& Osman, S. (2014). The Use of a Flipped Classroom to Enhance Engagement and Promote Active Learning. Journal of Education and Practice, 5(2), 124-131. Recuperado de http://iiste.org/Journals/index.php/JEP/article/view/10648

Ley Orgánica 8/2013, de 9 de diciembre, para la mejora de la calidad educativa. (BOE de 10 de diciembre de 2013).

López-Pastor, V.M. (coord.)(2006). La evaluación formativa y compartida en Educación Física. De la crítica al modela tradicional a la generación de un sistema alternativo. Revisión de 12 años de experiencia. Lecturas: Educación Física y Deportes, Revista Digital, 10, 94. Recuperado de http://www.efdeportes.com/efd94/eval.htm .

Pérez-Pueyo, A. (coord.) (2013). Programar y evaluar competencias básicas en 15 pasos. Barcelona: Graó.

Pérez-Pueyo, A., \& Casado, O. M., (2015). Escala graduada para la valoración de un video-tutorial. Recuperado de http://www.grupoactitudes.com/\#!competenciasbsicas-nueva/c1dub

Prieto, A. (2016). Flipped clasroom ¿¿cuáles son sus ventajas? ¿Cuál es su origen? [Web blog post]. Recuperado de http://profesor3punto0.blogspot.com.es/2016/07/flipped-classroom-cuales-son$\underline{\text { sus.html }}$

Real Decreto 1105/2014de 26 de diciembre, por el que se establece el currículo básico de la Educación Secundaria Obligatoria y del Bachillerato. 
Viñas, M. (2011). Khan Academy: Una nueva manera de enseñar matemáticas y más.

[Web blog post]. Recuperado de

http://www.totemguard.com/aulatotem/2011/05/khan-academy-una-nueva-

manera-de-ensenar-matematicas-y-mas/ 